Theory

\title{
Narrative Identity's Nomological Network: Expanding and Organizing Assessment of the Storied Self
}

\author{
William Dunlop ${ }^{1,2}$
}

[1] Department of Psychology, University of California, Riverside, CA, USA. [2] Department of Psychology, Aarhus University, Aarhus, Denmark.

Personality Science, 2021, Vol. 2, Article e6469, https://doi.org/10.5964/ps.6469

Received: 2021-03-30 • Accepted: 2021-07-04 • Published (VoR): 2021-08-12

Handling Editor: Sumaya Laher, University of the Witwatersrand, Johannesburg, South Africa

Reviewing: Round 1 - Anonymous \#1; Anonymous \#2. No open reviews are available

Corresponding Author: William Dunlop, Department of Psychology, University of California, Riverside, CA 92521, USA. E-mail: wdunlop@ucr.edu

\begin{abstract}
The life story, or narrative identity, is a psychosocial construction that brings together and integrates the self and experience within a broad story-based framework. Personality psychologists typically capture aspects of this inner story by prompting participants for descriptions of life chapters and/or specific and self-definitional autobiographical key scenes (e.g., high points, low points, turning points). Features of participants' responses are then quantified for their thematic and/or structural content. There exists a number of additional and complementary assessment techniques that could buttress study of, and theory pertaining to, narrative identity. Here, I work to identify these assessments, which include self-reports, informant reports, and behavioral observations, and organize them within narrative identity's nomological network. This work concludes with a number of suggestions for the ways in which traditional assessments may be better attuned to capture narrative identity's integrative nature.
\end{abstract}

\section{Keywords}

life stories, narrative identity, nomological network, assessment 


\section{Relevance Statement}

The field of narrative identity is at a unique an enviable crossroads. We have now amassed a sizable literature demonstrating that our typical approach for assessing features of participants' storied identities (in which we prompt for oral or written descriptions of key scenes and then quantify the resulting text for certain thematic and structural features) is valid. One path forward consists of continuing with this more-or-less standard assessment paradigm. A second path consists of expanding our assessments, beyond the analysis of text, to capture narrative identity's broader nomological network. This theoretical review explores the second of these paths. As such, it holds relevance to narrative identity researchers, those who wish to better incorporate the study of narrative identity in their work, and personality psychologists interested in measurement and assessment.

\section{Key Insights}

- The assessment of narrative identity is reviewed.

- Suggestions are made for the expansion of assessment within the narrative identity literature.

- These suggestions are organized on the basis of data category.

- These suggestions also touch on ways to target narrative identity's integrative nature.

The life story, or narrative identity, is a psychosocial construction of the personal past, present, and presumed future. While working to write this story, the author integrates and unifies representations of the self and experience within a coherent and compelling temporal arc. On the basis of its temporal-focus and integrative nature, narrative identity may be distinguished from other constructs in personality's pantheon (e.g., Syed et al., 2020). Narrative identity is a distinct level of personality (McAdams, 2013; McAdams \& Pals, 2006) and represents the centerpiece of a distinct personality assessment paradigm (e.g., Wiggins, 2003). There now exists a coherent and empirically solid literature examining the structure and features of narrative identity, one complete with a number of more-or-less standard assessment techniques to capture participants' broad life chapters and the specific and salient moments from within them and a number of more-or-less standard coding procedures to reliably quantify the content and structure of the resulting narrative material (see Adler et al., 2016, 2017; McLean, Syed et al., 2020). No matter where one finds themselves within the field, they are never far from narrative theories and narrative methods.

In this review I consider the first of these constituents - the assessment procedures used to capture narrative identity. The standard assessment technique consists of prompting participants for either oral or written stories about their lives, transcribing these responses (in the case of oral responses), and then reliably quantifying certain thematic and structural elements in the resulting text (Adler et al., 2017). So much as there is a central thesis or argument furthered here it is that the study of narrative 
identity currently occupies the unique and enviable sweet spot of having both 1) a proven assessment technique from which to assess content relevant to an understanding of its central construct, and 2) the opportunity to build upon and extent this assessment by incorporating methods capable of capturing aspects of story and storyteller that the analysis of the written record alone cannot. The majority of the words I have at my disposal are dedicated to point (2).

\section{Personality Psychology's Seismic Shift to Story}

What a difference 30 years makes. If we were to revisit the early 1990 s, the number of works exploring life stories or narrative identities within personality science could likely be counted on the hands of Dan McAdams, the author of most of them (e.g., McAdams, 1985, 1987, 1990). Within his Life Story Model of Personal Identity (McAdams, 1985)

It is an individual's story which has the power to tie together past, present, and future in his or her life. It is a story which is able to provide unity and purpose. It is a story which specifies a personal 'niche' in the adult world and a sense of continuity and sameness across situations and over time. (pp. 17-18)

Identity takes the form of an internal and evolving story, one constructed to bring together and integrate the many things seen, done, and experienced in a coherent, meaningful, and purposeful manner.

Since the 1990s, study of narrative identity has been broadened and built. One of the facilitators of its ascension has been the widespread adoption of portions of the Life Story Interview (LSI; McAdams, 2008) as a means of capturing features of narrative identity. In the full semi-structured LSI, consenting participants are asked to complete a number of related tasks, including the provision of a 15-20 minute overview of the major chapters in their lives and the recount of several specific key autobiographical scenes from their pasts, including high points, low points, and turning points. Through this assessment, researchers work to bring participants' internal life stories into the realm of the observable. Narrative descriptions are audio recorded and then transcribed verbatim. These and similar tasks have proven amenable to administration via printed and computer-mediated questionnaire (see Blagov \& Singer, 2004; Jensen et al., 2020; McCoy \& Dunlop, 2016; Thomsen et al., 2020). Researchers have typically focused on portions of the LSI in their assessments of narrative identity, notably descriptions of life chapters or key scenes. Irrespective of whether an interview or questionnaire methodology is used, the resulting text typically serves as the basis of subsequent analyses. Trained independent coders read each chapter and/or specific scene and then reliably quantify their thematic and structural features (for review, see Adler et al., 2017). For example, researchers often determine whether participants' stories are redemptive in 
nature, meaning that they possess a narrative arc characterized by a bad or affectively negative beginning giving way to a good or affectively positive ending (see Dunlop, 2021; McAdams, 2013).

There are many reasons why the aforementioned approach represents the default within the narrative identity literature. No alternative rivals its directness - if we want to get some measure of individuals' life stories, we should ask for them. Furthermore, the narrative material disclosed throughout the LSI holds the greatest known potential to capture the integrative nature of narrative identity. Distinct from the constructs housed within other conceptual levels (see McAdams \& Pals, 2006) and assessment paradigms (see Wiggins, 2003), narrative identity is uniquely qualified to speak to the chronologically coherent world building and myth making adults engage in when working to understand themselves, their lives, and the enveloping social worlds (e.g., Syed et al., 2020). The transcripts documenting the external manifestation of these inner stories, in turn, are uniquely qualified to speak to the nature of narrative identity. Finally, the data generated in concert with this approach is equal parts fascinating, telling of participants' personalities, and valid. Time and time again, the objective quantification of thematic and structural features within participants' stories has proven itself viable. The variables derived using this approach have been found to correspond reliably with a number of processes and outcomes that psychologists care about (for review, see Adler et al., 2016).

\section{Narrative Identity's Nomological Network}

All of the above being said, there is a sizable amount of useful information about our participants, their stories, and the interview process beyond this invaluable text. A short but non-exhaustive list of possible constructs that may bolster and supplement traditional assessments include participants' perceptions regarding the degree to which the notion of 'life as story' is relevant to them (e.g., Hallford \& Mellor, 2017), participants' evaluations of their own stories (e.g., Jensen et al., 2020) as well as their subjective experiences while reliving and retelling them (e.g., Luchetti \& Sutin, 2016), the emotional and stress-based responses demonstrated throughout the assessment process (e.g., Harringan et al., 2005), and the manner in which these stories fit within their broader social networks and narrative ecologies (e.g., Thomsen \& Pillemer, 2017). In this sense, it is less a matter of struggling to find additional constructs that are well-placed within the narrative identity literature, and more a matter of organizing them in some coherent manner.

Thankfully, there are several frameworks to arrange the types of data in which personality psychologist are typically interested. For example, the data most commonly considered in the narrative identity literature (i.e., the reliably quantified thematic and structural features of life chapters and key scenes) would be classified as BEHAVIORAL in nature, or B-Data as per Funder (2019). In Funder's organizing framework, behavioral data represents one category of data, to be considered alongside three others: SELF-REPORT (S-data), INFORMANT-REPORT (I-data), and LIFE OUTCOME (L-data), 
with S-data, I-data, and B-data being particularly relevant to issues of measurement and assessment. Personality psychologists in other areas (e.g., Luchetti \& Sutin, 2016), and researchers working outside of the field (e.g., Berntsen \& Rubin, 2006) have introduced a number of assessment and measurement strategies generating S-data, I-data, and B-data that hold relevance to narrative identity.

Relevance, of course, can take many different forms. In one form, these additional assessments and the constructs they generate hold relevance to narrative identity precisely because they capture features of this construct that the traditional assessment technique cannot. An implication of embracing this form of relevance would be the rebranding of narrative identity as fundamentally multi-modal in nature, with equal rights being afforded to those professing to study it using traditional methods as well as those more interested in, say, the nonverbal behaviors demonstrated during the storytelling process. In another form, these additional assessments and the constructs they generate hold relevance to narrative identity precisely because they represent distinct nodes within this construct's broader nomological network, rather than features of narrative identity itself. An implication of embracing this form of relevance would be that the additional assessments outlined here would become supplemental to the traditional assessment procedure.

Both orientations hold merit. Furthermore, the reader will likely come to conclude that some of the constructs reviewed in the pages that follow appear more tethered to narrative identity itself whereas others seem rightly placed within its conceptual orbit. Pragmatically, however, a paper that attempts to straddle a line between each of these forms of relevance while reviewing the material that follows is destined to itself be divided. With this in mind, while also drawing from the belief that the traditional assessment technique is both 1) the closest we can get to participants' inner stories, and 2) holds the greatest potential to capture narrative identity's integrative nature, I adopt the 'nomological network' stance in this review (see Figure 1). In the case of each category of data reviewed, I will note some of the ways in which the constructs considered can help address a number of pressing questions regarding narrative identity. Reference will also be made to a particular narrative theme, redemption, to illustrate the manner in which these additional assessment techniques can bolster understanding of narrative identity. 
Figure 1

Representation of Narrative Identity's Nomological Network

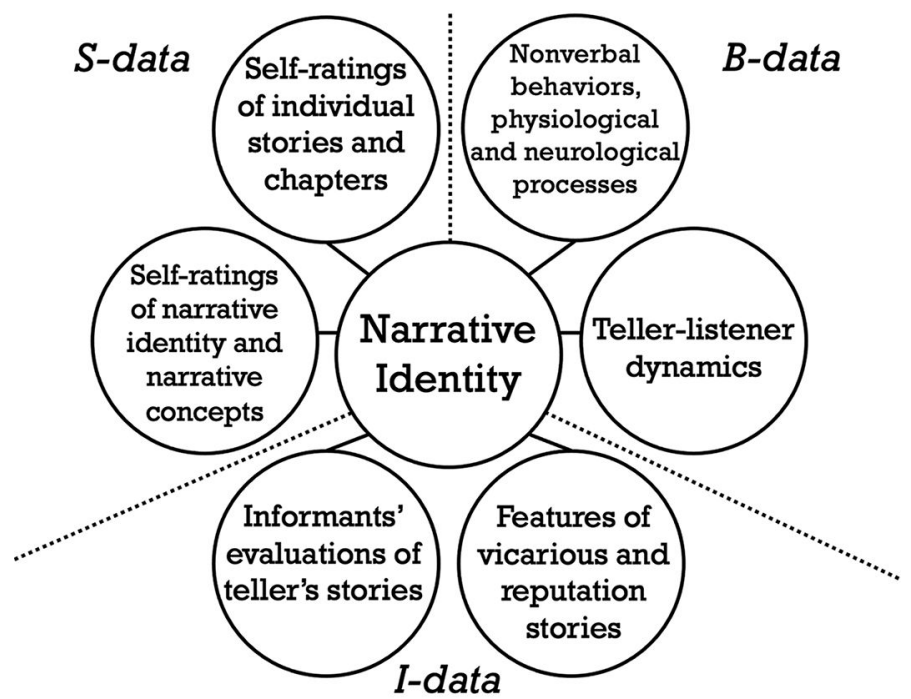

Note S-data $=$ self-reports; $\mathrm{B}$-data = behavioral-reports; $\mathrm{I}$-data $=$ informant data.

\section{S-Data}

The irony of a personality psychologist proclaiming that we need to do more to incorporate self-report data in our research does not escape me (e.g., Boyd et al., 2020). Narrative identity is conceptualized as the internal and evolving story one forms in the interest of establishing a sense of unity across contexts and continuity through time. As such, getting a signal of this internal story via the chapters and scenes participants produce when asked for them represents a viable approach. There is the story, though, and then there are the narrators' perceptions and evaluations of the story, as well as their experiences throughout the storying process. How do participants perceive their own stories? How frequently do they think about them? How vividly do they experience them? What relevance to they attribute to them? Through the collection of S-data, we could better explore these and similar questions.

\section{Self-Report Scales From Narrative Identity and Autographical Memory Literatures}

Implicit in the current assessment approach is the assumption that the notion of 'life as story' is similarly applicable to all who take part in our studies. To begin to determine whether this is in fact so, narrative identity researchers could assess participants' responses to questions concerning the degree to which they view their lives as stories. Evident from the information presented in Table 1, there are a small number of questionnaires 
that have been designed for this purpose. For example, in the Awareness of Narrative Identity Questionnaire (ANIQ; Hallford \& Mellor, 2017), participants are prompted to rate a number of items tapping their beliefs regarding the 'awareness' of narrative (e.g., "My memories are like stories that help me understand my identity") whereas the Love and Story and Storytelling questionnaire (LASS; Dunlop, 2019) contains a scale that may be used to assess perceptions regarding the degree to which respondents view their romantic relationships as if they were stories (e.g., "I often think about my romantic relationship as if it were a story, complete with characters and a plot"). This measure can be easily adapted to other relationships and domains (e.g., one's professional life/career) and life more broadly. It is not inconceivable that some degree of narrative 'gravity' could be inferred based on the types of stories participants produce when asked about their inner story (e.g., perhaps more coherent stories indicate a greater endorsement in the belief of life as story?), but this does not diminish the value of asking participants for their take on the matter.

\section{Table 1}

Description of Self-Report Questionnaires From the Narrative Identity and Autobiographical Memory Literatures

\begin{tabular}{|c|c|c|}
\hline Brief description & Scale & Subscales and sample items \\
\hline
\end{tabular}

\section{Narrative identity literature}

Awareness of Narrative Identity Questionnaire (ANIQ; Hallford \& Mellor, 2017)
A 20-item measure assessing
Eleven-point Likert-
Four subscales: awareness ("My memories are like the degree respondents believe they think about themselves type scale ranging stories that help me understand my identity"), and their lives in story-based ways as well as the degree of from 0 (completely disagree) to 10 temporal coherence ("I can put the events of my life in order of when they occurred"), causal coherence ("I coherence felt while so doing. (completely agree). understand how the story of my life unfolded"), and thematic coherence ("When I think or talk about experiences in my past I can see themes about the kind of person that I am").

Love as Story and Storytelling (LASS; Dunlop, 2019)

$\begin{array}{ll}\begin{array}{l}\text { An 8-item measure assessing } \\ \text { the degree to which }\end{array} & \begin{array}{l}\text { Five-point Likert- } \\ \text { type scale ranging }\end{array} \\ \text { participants enjoy sharing } & \text { from 1 (disagree } \\ \text { autobiographical stories with } & \text { strongly) to 5 (agree } \\ \text { their romantic partners as well } & \text { strongly) } \\ \text { as think about their romantic } & \\ \text { relationships as if they were } & \\ \text { stories. }\end{array}$

Two subscales: storytelling enjoyment ("When spending time with my romantic partner, we tend to reminisce about our shared experiences") and narrative mindset ("I often think about my romantic relationship as if it were a story, complete with characters and a plot"). 


\begin{tabular}{|c|c|c|}
\hline Brief description & Scale & Subscales and sample items \\
\hline \multicolumn{3}{|c|}{ Redemption and Contamination Research Form (RCRF; Dunlop, Wilkinson et al., 2020) } \\
\hline $\begin{array}{l}\text { A 19-item measure assessing } \\
\text { the degree to which } \\
\text { respondents view their lives } \\
\text { and worlds in redemptive and } \\
\text { contaminated ways. }\end{array}$ & $\begin{array}{l}\text { Five-point Likert- } \\
\text { type scale ranging } \\
\text { from } 1 \text { (disagree } \\
\text { strongly) to } 5 \text { (agree } \\
\text { strongly). }\end{array}$ & $\begin{array}{l}\text { Two subscales: redemptive mindset ("When something } \\
\text { bad happens to me, it usually leads to something } \\
\text { good") and contaminated mindset ("When something } \\
\text { good happens to me, it usually leads to something } \\
\text { bad"). }\end{array}$ \\
\hline
\end{tabular}

Autobiographical memory literature

\section{Autobiographical Recollection Test (ART; Berntsen et al., 2019)}

A 21-item measure assessing

"features typically associated with the recollective qualities of autobiographical memories" (p. 307).
Seven-point Likert- Seven subscales: reliving ("When remembering past type scale ranging events, it is as if I am reliving them"), vividness ("My from 1 (strongly disagree) to 7 (strongly agree). memories of past events have a lot of details"), visual imagery ("While remembering past events, I can see them in my mind"), scene ("In my memory of past events, I remember where the actions, objects, and people are located in the events"), narrative coherence ("My memories of past evets come to me as good stories or descriptions"), life story relevance ("My memories of past events are a central part of my life story"), and rehearsal ("I often think back to my past events in my mind and think or talk about them").

Involuntary Autobiographical Memory Inventory (IAMI; Berntsen et al., 2015)

A 20-item measure assessing the frequency of involuntary autobiographical memories and future-oriented thoughts.

Reminiscence Functions Scale (W

A 43-item measure assessing respondents' perceptions regarding the uses, or functions, of reminiscence.
Four-point scale ranging from 0

(never) to 4 (once an hour or more).
When I am relaxing or doing routine work, imaginary future events come to my mind - without me consciously trying to evoke them.

\section{(Webster, 1997)}

Six-point Likert-type Eight subscales: boredom reduction ("to reduce scale ranging from 1 boredom"), death preparation ("because it helps me see (never) to 6 (very that I've lived a full life and can therefore accept death frequently). All items more calmly"), identity ("to try to understand myself are interpreted with better"), problem-solving ("to help resolve some respect to the current difficulty"), conversation ("to create ease in following stem: conversations"), intimacy maintenance ("to remember "When I reminisce it someone who passed away"), bitterness revival ("to is..." keep memories of old hurts fresh in my mind"), and teach/inform ("to teach younger family members what life was like when I was young and living in a different time"). 


\section{Brief description}

Scale

Subscales and sample items

\section{Survey of Autobiographical Memory (SAM; Palombo et al., 2013)}

A 26-item measure assessing perceptions of memory functions.
Five-point Likerttype scale ranging from 1 (strongly disagree) to 5 (agree strongly).
Self-Concept Focus (Rubin, 2020)

\begin{tabular}{|c|c|}
\hline $\begin{array}{l}\text { A } 15 \text {-item measure assessing } \\
\text { respondents' tendency to } \\
\text { recognize autobiographical } \\
\text { memories are central to the self } \\
\text { and frequently rehearsed. }\end{array}$ & $\begin{array}{l}\text { Five-point Likert- } \\
\text { type scale ranging } \\
\text { from } 1 \text { (totally } \\
\text { disagree) to } 5 \text { (totally } \\
\text { agree). Participants } \\
\text { are asked to } \\
\text { complete three } \\
\text { questions each in } \\
\text { relation to six } \\
\text { events. }\end{array}$ \\
\hline
\end{tabular}

Four subscales: episodic ("When I remember events, in general I can recall objects that were in the environment"), semantic ("I can learn and repeat facts easily, even if I don't remember where I learned them"), spatial ("In general, my ability to navigate is better than most of my family/friends"), and future ("When I imagine an event in the future, the event generates vivid mental images that are specific in time and place").

This event has become a reference point for the way I understand new experiences.

Thinking about Life Experiences scale (TALE; Bluck \& Alea, 2011)

A 15-item measure assessing respondents' perceptions regarding the uses, or functions, of their memories.
Five-point Likerttype scale ranging from 1 (almost never) to 5 (very frequently). All items are interpreted with respect to the following stem: "I think back over or talk about my life or certain periods of my life..."
Three subscales: self-continuity function (“...when I want to feel that I am the same person I was before”), social-bonding function (“...when I hope to also find out what another person is like"), and directingbehavior function (“...when I want to remember something that someone else said or did that might help me now").

Note. Sample items were selected on the basis of their placement within original texts. Where applicable, the most recent version of questionnaires is summarized.

Table 1 reveals a broader truth regarding the current state of affairs in the narrative identity literature: When it comes to the development and application of self-report measures relevant to all things autobiographical, we have been outpaced by those working in the autobiographical memory field (e.g., Berntsen et al., 2015; Berntsen et al., 2019; 
Webster, 1997). Thankfully, many of the measures emerging from the autobiographical memory literature and described in Table 1 could be readily applied to study of narrative identity. Consider, for example, the Autobiographical Recollection Test (ART; Berntsen et al., 2019). The ART contains seven subscales, each of which may be used to help explore certain components of narrative identity's nomological network distinct from the stories our participants choose to share with us. These include the degree to which participants feel as though they are reliving previous experiences when reflecting upon them (e.g., "When remembering past events, it is as if I am reliving them"), the degree to which these previous events are considered (e.g., "I often think back to me past events in my mind and think or about them"), and the degree to which personal memories hold relevance to their storied selves (e.g., "My memories of past events are a central part of my life story").

Why the narrative identity and autobiographical memory literatures talk to each other so infrequently is a topic for another time. Here, it is enough to frame the various memory-based questionnaires circulating in the autobiographical memory literature as a largely untapped resource. It is meaningful whether our participants believe they view their pasts frequently as compared to infrequently, vividly as compared to drably, and/or intensely as compared to temperately. These individual differences speak to a node within narrative identity's nomological network adeptly captured with S-data.

S-data could also be considered in relation to features of participants' stories themselves, as well as the associations these self-perceptions and stories share with the outcome(s) of interest. For example, it would be informative to determine whether those who tend to disclose redemptive stories are the same people who indicate a willingness or awareness to think about their lives as if they were stories (assessed using the 'awareness' subscale of the ANIQ; Hallford \& Mellor, 2017), report frequently thinking about the past (assessed using the 'rehearsal' subscale of the ART; Berntsen et al., 2019), and/or believe they think about the past in an effort to work through current problems (assessed using the 'problem-solving' subscale of the Reminiscence Function Scale [RFS] Webster, 1997).

Finally, it is worth noting that there are likely many important self-report measures that have yet to be written. For example, an unexplored dimension relevant to traditional assessments of narrative identity is the degree to which the stories participants generate in concert with the LSI and/or prompts for written responses represents an active process of self-making as opposed to a well-rehearsed press release of sorts. The former speaks to narrative's ability to integrate self and experience in the moment. The latter brings us closer to the metaphor of life as performance and all things dramatological. S-data may be used to become clearer on which possibility is at play in a given assessment. Following their assessment, participants could be prompted to evaluate a number of prespecified items pertaining to their experiences throughout (e.g., "The questions I was asked in this interview led me to think about my life in novel ways", "Through 
this interview, I was able to share many experiences I frequently disclose to others"). This may help capture the degree to which participants were actively constructing their experiences before us relative to running us through their greatest hits.

\section{Story-Specific Self-Ratings}

Just as it is useful to get a sense of participants' broader evaluations regarding the relevance of story to their lives, the various ways they experience the past and the disclosure process, and the functions they believe such reminiscence serves, so too is it useful to assess participants' perceptions about their specific chapters, scenes, and memories. Drawing again from the narrative identity and autobiographical memory literatures, Table 2 presents a number of measures that could be administered to participants following their disclosure of each story. These measures show considerable breadth. Some target perceptions of the emotions experienced when reliving the memory in question (e.g., Blagov \& Singer, 2004), others assess the intensity of these emotions (e.g., Rubin et al., 2011), and others still focus the degree to which participants view the event as central to the self (e.g., Berntsen \& Rubin, 2006).

\section{Table 2}

Description of Story/Memory-Specific Self-Report Measures

Scale $\quad N_{\text {items }} \quad$ Subscales and sample items

Self-Defining Memory Task (Blagov \& Singer, 2004)

Seven-point Likert-type scale ranging 15 Five subscales; positive emotions ("happy"), negative

from 0 (not at all) to 6 (extremely) emotions ("sad"), vividness ("vivid"), importance

("important"), and years ago ("How many years ago did the memory take place?").

Unnamed measure (Berntsen \& Bohn, 2010)

Five-point Likert-type scale; Seven-

point Likert-type scale; Varying anchors
1414 single-item subscales from which two aggregate subscales may be derived: imagery ("This memory is vivid"), and self-narrative, ("The remembered event is important to my life").

The Centrality of Events Scale (CES; Berntsen \& Rubin, 2006)

Five-point Likert-type scale ranging

from 1 (totally disagree) to 5 (totally

agree)
20/7 This event has become a reference point for the way I understand new experiences.

Unnamed measure (Dunlop, Harake et al., 2020)

$1 / 0$ (yes/no) and a five-point Likert-

type scale ranging from 1 (very

negative) to 5 (very positive)
Three single item subscales: redemption ("As personality psychologists, we are often interested in 'redemptive' personal stories. In a redemptive story, a 'bad' or emotionally negative event or circumstance leads to a 'good' or positive outcome. So, the story moves from a 


\begin{tabular}{|c|c|c|}
\hline Scale & $N_{\text {items }}$ & Subscales and sample items \\
\hline & & negative beginning to a positive ending. Based on this \\
\hline & & description, would you consider your self-defining memory \\
\hline & & redemptive?" [yes/no]), contamination ("We are also \\
\hline & & interested in 'contaminated' personal stories. In a \\
\hline & & contaminated story, a 'good' or emotionally positive event \\
\hline & & leads to a 'bad' or negative outcome. So, the story moves \\
\hline & & from a positive beginning to a negative ending. Based on \\
\hline & & this description, would you consider your self-defining \\
\hline & & memory contaminated?" [yes/no]), affective tone ("On the \\
\hline & & whole, how emotionally positive/negative is your self- \\
\hline & & defining memory?" [very negative/very positive]). \\
\hline
\end{tabular}

The Life Story Questionnaire (Jensen et al., 2020)

Five-point Likert-type scale ranging $\quad 7 \quad$ Six single-item subscales: positive tone ("To what extent from 1 (not at all) to 5 (very much) would you describe the specific memory as positive?"), negative tone ("To what extent would you describe the specific memory as negative?"), positive stability ("Does the specific memory highlight any positive attributes that characterize who you are?"), negative stability (“Does the specific memory highlight any negative attributes that characterize who you are?"), positive change ("Has the specific memory changed you in a positive way?"), and negative change ("Has the specific memory changed you in a negative way?").

The Memory Experiences Questionnaire (MEQ; Luchetti \& Sutin, 2016)

Five-point Likert-type scale ranging

from 1 (strongly disagree) to 5

(strongly agree)
31 Ten subscales: vividness ("My memory for this event is clear"), coherence ("The order of events in the memory is clear"), accessibility ("This memory was easy for me to recall"), time perspective ("My memory for the year when the event took place is clear"), sensory details ("As I remember the event, I can hear it in my mind"), visual perspective ("In my memory, I see the experience in the memory through my own eyes"), emotional intensity ("My emotions are very intense concerning this event”), sharing ("Since it happened, I have talked about this event many times"), distancing ("I feel like the person in this memory is a different person than who I am today"), valence ("The overall tone of the memory is positive").

Autobiographical Memory Questionnaire (AMQ; Rubin, Dennis, \& Beckham, 2011)

Seven-point Likert-type scale; Three- $\quad 21$ point Likert-type scale; Various anchors
21 single-item subscales housed within seven thematically linked categories: emotions ("While remembering, the emotions that I feel are extremely intense"), rehearsal ("Since it happened, I have thought or talked about this 


\begin{tabular}{|c|c|c|}
\hline Scale & $N_{\text {items }}$ & Subscales and sample items \\
\hline & & $\begin{array}{l}\text { event"), centrality ("The event in my memory is a central } \\
\text { part of my life story"), sensory and language processes } \\
\text { ("While remembering the event, I can see it in my mind"), } \\
\text { narrative ("It comes to me in words or in pictures as a } \\
\text { coherent story"), meta-cognitive judgements ("While } \\
\text { remembering the event, I feel as though I am reliving it"), } \\
\text { reported properties of events or memories ("The event } \\
\text { occurred once at one particular time (within a day) and } \\
\text { place"). }\end{array}$ \\
\hline
\end{tabular}

Note. Sample items were selected on the basis of their placement within original texts. Where applicable, the most recent version of questionnaires was summarized.

As an example of the ways in which S-data could help inform understanding of narrative identity, consider the Centrality of Events Scale (CES; Berntsen \& Rubin, 2006). Just as the awareness subscale of the ANIQ (Hallford \& Mellor, 2017) holds the potential to aid in the determination of the degree of relevance narrative identity possesses in our participants' hearts and minds, the CES could be used to measure each story's self-relevance. Doing so would allow us to explore potentially meaningful differences between participants who, for example, rate their life high point as central to their sense of self and life low point in the opposite manner, as compared to participants who feel as though their life high point speaks little to who they are and their low point is definitional or central to the self. On the basis of current conventions, such differences remain in our collective blind spot.

Incorporating measures of centrality at the story-level may help us better understand a surprising finding emerging from the published works examining narrative identity longitudinally. In this body of research, rates of twice-told stories (i.e., recognizing the same manifest event across assessments in response to the same prompt) are quite low (McAdams et al., 2006; Thorne et al., 1998). For example, McAdams and colleagues found that, even a few months after their initial participation, only about $20 \%$ of life events were repeated in participants' key scenes. Narrative identity researchers have yet to reach either understanding or consensus as to why some participants appear to always disclose the same old stories, whereas others seem to create a storied self anew every time we see them (see Adler, 2019).

Participants' perceptions of centrality could explain this vexing individual difference. It seems plausible to hypothesize that, all things being equal, stories rated as highly central will be more likely to appear across assessments, relative to those stories deemed less central to the self. To this point, however, no known study has attempted to explore the relation between subjective evaluations of stories (be it in terms of centrality or otherwise) and their tendency to be disclosed across multiple assessments. This represents 
but one way that a greater incorporation of self-ratings may help address fundamental questions regarding the nature of narrative identity, including the factors underlying its demonstrated continuity and change.

Those looking to better incorporate self-ratings of particular stories and memories have a number of options from which to choose (see Table 2). Given the little work that has explored self-evaluations of story in the study of narrative identity and in the absence of a research question pertaining to a particular self-reported construct, it may be prudent to start as broadly as possible, by incorporating into the study of narrative identity a measure like the Memory Experiences Questionnaire (MEQ; Luchetti \& Sutin, 2016). In the MEQ, participants are prompted to rate each memory or story generated in terms of a number of items housed within ten subscales. Many of these subscales speak to the dimensions recognized above (e.g., vividness and emotional intensity). In addition to considering these self-ratings in relation outcomes of interest, considerable gains could be made in fleshing out self-views of certain story types. Returning to the redemptive story, it would be interesting to know if, for example, relative to non-redemptive stories, redemptive stories are perceived more vividly, more often reflected upon, or viewed as particularly central to one's sense of self (see also, McLean \& Lilgendahl, 2008). As is the case with respect to the broader measures reviewed in Table 1, if their research questions so require, researchers should also consider creating new and novel story-specific self-report measures.

\section{Self-Reports of Story-Relevant Constructs and Summary}

A final manner in which S-data can be incorporated in study of narrative identity concerns the constructs often quantified in participants' stories. Recently, my research group has suggested that some of these constructs are likely broader than their manifestations within story (Dunlop, Wilkinson et al., 2020). Consider, once again the concept of redemption. In a redemptive story, affectively negative beginnings are salvaged or redeemed, leading to a positive ending. It is possible that the tendency to disclose this type of story is actually a central component of a broader and multi-modal personality characteristic defined by the tendency to view one's life and the enveloping social world in terms of a negative-to-positive arc. Seeking to assess this characteristic using S-data, my colleagues and I developed the Redemption and Contamination Research Form (RCRF) which contained items such as "When something bad happens to me, it usually leads to something good" and "Setbacks in life only make you stronger." Consistent with the rebrand of redemption as multi-modal in nature, we observed a positive relation between self-reports of redemptive mindsets and the tendency to disclose redemptive autobiographical stories.

In summary, self-reports and self-ratings of individual stories are well placed within narrative identity's nomological network. Through such an incorporation, we would be better equipped to capture participants' evaluations of the storied self, including its 
self-perceived relevance (e.g., Hallford \& Mellor, 2017), the intensity with which it is experienced (Berntsen et al., 2019), and the degree to which it is believed to serve a number of particular functions (e.g., Bluck \& Alea, 2011; Webster, 1997). These and other dimensions may also be explored at the individual story-level (e.g., Berntsen \& Rubin, 2006; Luchetti \& Sutin, 2016). This is an area of the narrative identity literature that is in the process of being written. Narrative identity researchers should also consider developing their own self-report measures to assess constructs of interest that are absent from Table 1 and Table 2.

\section{I-Data}

Of course, assessment does not and should not end with S-data. There are many things participants cannot or will not disclose through self-report (Paulhus \& Vazire, 2007). When faced with these limitations, personality psychologists have often pivoted away from collecting data from participants themselves and towards collecting information about them from those who know them best - their close contacts, or informants. When working with I-data, informant reports of participants' traits have been most frequently considered. This approach is best represented in the 'person perception' literature (for review, see Connelly \& Ones, 2010).

Person perception researchers have explored a number of topics, including the predictive ability and validity of informants' ratings of traits, the degree of agreement between informants and participants in trait ratings, as well as the factors that may boost or reduce this convergence. Painting with a broad summative brush, it appears that informant reports of traits are highly predictive of participants' personalities and corresponding L-data, relate significantly with each other (i.e., they demonstrate a high degree of informant consensus) and participants' self-ratings (i.e., they demonstrate a high degree of self-other agreement), and all things being equal, become more accurate with more information (e.g., Connelly \& Ones, 2010; Funder, 2019; Vazire, 2010).

When applied to the topic of narrative and narrative identity, there are ways in which the ethos of person perception does and does not translate. Within the realm of narrative identity, the notion of 'accuracy' is one concept that possesses only limited relevance. Narrative identities are 'psychosocial constructions' crafted on the basis of the occurrence of biographical events and infused with personal meanings, inferences, and interpretations (McAdams et al., 1997). It is these latter elements that are both 1) central to the notion of story itself (Bruner, 1986) and 2) often incapable of verification. Who is to say otherwise, for example, if a given narrator views the recovery from alcohol addiction as her life turning point? Or if she believes this event has caused a sizable development in her own character?

Certainly not her close social contacts. When we get down to brass tacks, it is the narrator who is the author of the story. This is by in no way shape or form meant to suggest, though, that narrators are immune to suggestion in the composition of their 
storied selves. On the contrary, like storytelling itself, much about narrative identity is social and cultural in nature. These stories exist within particular sociocultural niches, or narrative ecologies (McLean, 2015), which work to guide and constrain the manner in which they are disclosed and (re)composed. The redemptive story, for example, has been recognized as a master narrative within American cultural contexts, one that many may feel compelled to construct when faced with personal and collective challenges (see Dunlop, 2021; McAdams, 2013). Due to the weight placed on all things sociocultural, a consideration of I-data in the assessment of narrative identity is apt.

On a limited scale, researchers have begun to incorporate I-data within the narrative identity literature. This I-data has often functioned under the moniker of "vicarious life stories" (e.g., Harake, McCoy et al., 2020; Harake, Wilkinson et al., 2020; Panattoni \& Thomsen, 2018; Thomsen \& Pillemer, 2017; Thomsen et al., 2020) defined as "representations of the events, meanings, and themes that compose other individuals' life stories" (Thomsen \& Pillemer, 2017, p. 464). In a series of recent studies (Harake, McCoy et al., 2020), my research team and I prompted college students for nominations of up to four social contacts they had known for at least a year and with whom they frequently connected. In one of these studies, each participant was then asked to generate the manifest event that represented a life high point, low point, and turning point. Informants were prompted to complete a comparable assessment, but in reference to the participants' lives rather than their own (i.e., informants were asked to generate the manifest events that, they believed, participants would identify as their life high points, low points, and turning points). Measures of relationship closeness were also administered.

Participants and informants demonstrated consensus in the manifest events relevant to participants' narrative identities approximately $25 \%$ of the time, and this self-other consensus increased with reports of relationship closeness. Speaking on behalf of my colleagues and coauthors, this was one of those projects that just left you wanting more. Our results provided a very cursory snapshot of the relations between the stories held by the self and the stories attributed to the self by the other(s). It raised a number of questions regarding the potential dynamics by which narrative identities are negotiated, sustained, and refuted (see also, McLean, 2015). It seems likely that a certain tension exists when individuals' stories do not align with the stories attributed to them by close others. One way to alleviate this tension would be to change one's story. Another would be to shape the vicarious stories present in the narrative ecology. Like the incorporation of self-ratings of participants' chapters and key scenes, I view the incorporation of I-data in subsequent longitudinal research on narrative identity as a potential route by which we could arrive at a better understanding of continuity and change.

An additional 'hot topic' issue in the study of vicarious life stories is a question of whether these psychosocial constructions represent an understanding of another's story relative to a projection of one's own (see also Dunlop et al., 2018). To date, the cleanest empirical test of these possibilities comes to us from Panattoni and Thomsen (2018; see 
also, Thomsen et al., 2020). In this work, the authors requested key scenes from both members of intact romantic couples. The authors also asked participants to specify the key scenes they attributed to their partners' life stories (i.e., the key scenes they thought their partners would tell). Coding the resulting narrative material for agency (themes of self-mastery, status/victory, achievement/responsibility, and empowerment), communion (themes of love/friendship, dialogue, caring/helping, and unity/togetherness), and redemption, Panattoni and Thomsen provided evidence for both of these possibilities. A positive relation was noted between the three narrative themes considered in personal stories and the stories participants attributed to their partners (suggesting projection). In the case of agency and communion, a significant degree of correspondence was noted between participants' vicarious stories and the personal stories of their partners (suggesting other-understanding).

One read of these results is that narrators' own storytelling style may impact the ways they tell the stories attributed to close others. That being said, with respect to certain themes (in this case, agency and communion), narrators also demonstrate an ability to see the other from the inside out, telling stories in a manner that align with others' own story-based framings. Emerging evidence also exists for the unique predictive ability of aspects and features of vicarious life stories relative to participants' own key scenes (Harake, Wilkinson et al., 2020) and the implications vicarious life stories may hold for relationship closeness (Harake, McCoy et al., 2020). It appears, then, that there is something unique and important about the understanding of others' stories about others.

Researchers have begun to incorporate a consideration of vicarious life stories within the narrative identity literature (e.g., Harake, McCoy et al., 2020; Thomsen \& Pillemer, 2017; Thomsen, Panattoni et al., 2020). Among those who know us best, however, the manner in which our own narrative identities are perceived represents but a portion of our broader reputations. In future, assessments of vicarious life stories could be enhanced by requests for informants' self-definitional stories about participants themselves (i.e., their other-definitional stories). These stories in particular - the stories that are told about us - may work to constrain the ways in which our own stories are told (McLean, 2015). As of this writing, a consideration of such 'reputation stories' remain largely absent in the narrative identity literature.

An additional manner in which I-data is beginning to be incorporated in the study of narrative identity pertains to the solicitation of informants' ratings of participants' stories (e.g., McLean, Delker et al., 2020; see also, McLean et al., 2017). In the assessment paradigm introduced by McLean, Delker and colleagues (2020), participants were presented with a number of personal narratives and then asked to rate these stories, as well as the narrators, along various dimensions (see also, Dunlop, Lee et al., 2020). Redemptive stories about personal traumas as well as the people who told them were judged more favorably than non-redemptive stories and storytellers. To be clear, McLean and colleagues did not present close social contacts with the stories generated by the 
participants these informants personally knew. In future, however, this could be done to arrive at some indication of the features of participants' narrative identities that are supported and contested within their narrative ecologies.

In summary, narrative identity is often framed as relational and dynamic in nature. Thus far, our methods have been outpaced by these writings. This appears to be changing. A consideration of the stories attributed to participants by close others (vicarious life stories), the stories these close others tell about participants (referred to here as reputation or other-definitional stories), and close others' evaluations of participants' stories themselves, holds considerable promise. Through the incorporation of such I-data, we can get some sense of participants' broader narrative ecologies. Doing so will likely inform our understanding of the nature of participants' narrative identities.

\section{B-Data}

When the LSI is administered as a semi-structured interview, responses are audio recorded, transcribed verbatim, and the resulting text is objectively quantified. As a field, narrative identity researchers have done little to measure the various nonverbal behaviors that manifest throughout this assessment procedure. This is a particular unfortunate oversight given the richness of this type of data (see Harringan et al., 2005), the intimate relation between narrative, storytelling, and the body (e.g., Pasupathi, 2015), and the impact that interpersonal dynamics exhibit on what, and in what way, personal information is disclosed (e.g., Bamberg, 2015; McCoy \& Dunlop, 2016). In other words, B-Data represents a viable yet largely underexamined features of narrative identity's nomological network.

There are many ways in which study of nonverbal behaviors could be incorporated into the narrative identity literature. Beginning with an assessment context devoid of videography, there is likely useful information contained on the interview's audio file that is not reflected in the resulting transcript. Even stripped of content (i.e., content-filtered), vocal tone, for example, has been found to provide a reliable indicator of affect. Methods exist to quantify content-filtered speech in naturalistic conversations for a variety of constructs including warmth/pleasantness, anger/hostility, and anxiety/nervousness (see Haskard et al., 2008). These methods could be adopted to quantify the affective quality of participants' vocalizations as they respond to LSI prompts.

Of course, just as narrators are more than the text they provide, they are also more than the vocal tones they display throughout the course of an LSI. The ability to map the nonverbal behaviors present during this interview is enhanced if it is video recorded. For example, through a consideration of recorded facial expressions, many of which having been proven capable of being reliably quantified using automated computer programs as well as manual coding (see Skiendziel et al., 2019), researchers could document the emotions participants experience and express as they share their stories, as well as the degree to which these expressions do or do not align with the affect captured via 
content-filtered vocal tone (see Harringan et al., 2005) and the emotional tone identified in the resulting transcript.

Shifting from participants to their interactions with interviewers, researchers with an interest in narrative identity's nomological network have much to draw from the literature exploring nonverbal behaviors as manifest in clinical and counseling settings. Within this substantive area, established methods exist to quantify the orientation participants and interviewers demonstrate towards each other (e.g., the position of their arms and legs, the presence/absence of a forward lean, the degree of eye contact) as well as the degree of rapport they share (for review, see Hall et al., 1995). Outside of clinical and counseling contexts, there are validated coding systems to capture features of the behaviors participants demonstrate when interacting with others (in this case, interviewers). In the Riverside Behavioral Q-sort (Funder et al., 2000), for example, the social behaviors demonstrated by the participant and interviewer could be captured along a number of dimensions, including the degree to which the participant "appears to be relaxed and comfortable" and "exhibits an awkward interpersonal style". Certain assessment techniques derived in concert with Contemporary Integrative Interpersonal Theory (see Hopwood et al., 2021) are similarly relevant. For example, the computer-mediated coding system reported by Sadler and colleagues (2015) allows for the quantification of dominant and affiliative behaviors demonstrated with the storyteller and the interviewer, in real time.

Measures of physiological processes, including heartrate and electrodermal activity should also remain in the mix in the study of narrative identity. These measures are capable of mapping responses to stress (see Pressman et al., 2020). As such, they would have something to tell us about participants' experiences while disclosing stories drawn from their narrative identities. Finally, we may also wish to more thoroughly consider potential associations between narrative and neuroscience (or narrative neuroscience). There is an emerging area of research exploring autobiographical memory using functional neuroimaging (fMRI; see, e.g., Cabeza \& St Jacques, 2007; D’Argembeau et al., 2014; Willems et al., 2020), from which certain methods could be adapted and/or adopted. Although the ability to engage with story and storytelling in an ecologically valid manner while in a fMRI scanner is no doubt compromised, on this basis of one's research interest, this cost may be outweighed by the gains made in understanding the brain activity at play during autobiographical memory retrieval and disclosure.

Consideration of the aforementioned behavioral data would allow for exploration of many constructs and processes pertinent to narrative identity. This is true both with respect to an entire LSI (i.e., the mean-level of these nonverbal behaviors in response to all prompts) as well as at the prompt-level and within-stories. For example, with such data in hand, we could begin to map out the affective nature of particular types of stories (e.g., the emotions associated with the disclosure of a redemptive story) and consider the way(s) in which these nonverbal behaviors align with (or diverge from) what is said. The 
main point of doing so would be to get a better sense of how self and story are embodied. This would address calls to broaden the manner in which we conceptualize identity to include bodies, emotional experiences, and the social dynamics of which we are a part (e.g., Bamberg, 2015; Pasupathi, 2015). Many of the constructs recognized above have also been found to correspond with outcomes that are of interest to personality psychologists (e.g., mental and physical health; Haskard et al., 2008) Fleshing out narrative identity's nomological network, then, to better incorporate B-data relevant to the disclosure of narrative identity, may also aid in our ability to account for important processes and outcomes.

\section{Summing It All Up, Looking Ahead}

In their conceptual review, McAdams and Pals (2006) drew an analogy between authoring a narrative identity and selecting a meal from a prespecified menu. This analogy was meant to signal the fact that 1) culture constrains the types of stories we can tell, and 2) within this finite list of permitted stories, some personal agency exists in the selection of the structures and motifs used to understand one's own live and the lives of others.

The written record of the stories participants share with us will always be the main course in the study of narrative identity. Period. This is the most direct signal we can get of participants' inner stories. In addition, the text participants generate while storying their lives holds the greatest potential to speak to narrative identity's temporal and integrative nature (see also, Syed et al., 2020). The driving impetus of this methodological review was to signal a number of additional assessments pertinent to narrative identity. I have considered these potential supplemental assessments in terms of S-data (self-report measures, story-specific and otherwise), I-data (social contacts' representations and evaluations of participants' stories) and B-data (nonverbal behaviors, physiological and neurological processes; see Figure 1). The data resulting from them may better capture features of narrative identity's nomological network and the storytelling experience that text-based analyses miss (for a summary, see Table 3). This broader orientation will only help us form a more compelling and complete story about the self, story, and the relation between the two. 
Table 3

Summary of Methodologies That May Be Used to Supplement the Assessment of Narrative Identity

\begin{tabular}{|c|c|c|c|}
\hline Construct & Assessment & Brief description & Additional reading \\
\hline \multicolumn{4}{|c|}{ S-data } \\
\hline $\begin{array}{l}\text { Perceptions of } \\
\text { relevance and } \\
\text { features of self, } \\
\text { narrative, and } \\
\text { memory }\end{array}$ & $\begin{array}{l}\text { Self-report } \\
\text { questionnaire }\end{array}$ & $\begin{array}{l}\text { Participants are asked to rate prespecified items } \\
\text { assessing the degree to which, they believe, } \\
\text { their lives are story-like, and other features of } \\
\text { their stories and/or memories. }\end{array}$ & $\begin{array}{l}\text { Hallford \& Mellor } \\
\text { (2017) }\end{array}$ \\
\hline $\begin{array}{l}\text { Perceptions of } \\
\text { relevance and } \\
\text { features of } \\
\text { individual stories } \\
\text { and memories }\end{array}$ & $\begin{array}{l}\text { Self-ratings of } \\
\text { stories }\end{array}$ & $\begin{array}{l}\text { Following the generation of an } \\
\text { autobiographical story or memory, participants } \\
\text { are asked to evaluate this text along various } \\
\text { dimensions, as measured by their ratings to a } \\
\text { number of prespecified items. }\end{array}$ & $\begin{array}{l}\text { Dunlop, Harake et } \\
\text { al. (2020) }\end{array}$ \\
\hline \multicolumn{4}{|c|}{ I-data } \\
\hline $\begin{array}{l}\text { Vicarious life } \\
\text { stories }\end{array}$ & $\begin{array}{l}\text { Social contacts' } \\
\text { telling of } \\
\text { participants' } \\
\text { narrative } \\
\text { identities }\end{array}$ & $\begin{array}{l}\text { Close social contacts are prompted to generate } \\
\text { the stories they believe are part of participants' } \\
\text { narrative identities. }\end{array}$ & $\begin{array}{l}\text { Thomsen \& Pillemer } \\
\text { (2017) }\end{array}$ \\
\hline $\begin{array}{l}\text { Story-based } \\
\text { reputation }\end{array}$ & $\begin{array}{l}\text { Social contacts' } \\
\text { stories about } \\
\text { participants }\end{array}$ & $\begin{array}{l}\text { Close social contacts are asked for self- } \\
\text { definitional stories about participants. }\end{array}$ & McLean (2015) \\
\hline $\begin{array}{l}\text { Perceptions of } \\
\text { stories from } \\
\text { participants' } \\
\text { narrative } \\
\text { identities }\end{array}$ & $\begin{array}{l}\text { Social contacts' } \\
\text { evaluations of } \\
\text { participants' } \\
\text { stories }\end{array}$ & $\begin{array}{l}\text { Close social contacts are prompted to read and } \\
\text { then rate participants' stories in terms of a } \\
\text { number of prespecified items. }\end{array}$ & $\begin{array}{l}\text { McLean, Delker et } \\
\text { al., (2020) }\end{array}$ \\
\hline
\end{tabular}

\section{B-data}

Affect experienced Content-filtered during interview vocal tone
The audio file used to capture participants' oral Haskard et al., (2008) responses is first content-filtered, removing what is said while retaining the vocal tone with which it is said. This content-filtered material may then be quantified for a number of affective dimensions.

Visual emotional Facial expressions, assessed either through expressions video file or still image, may be used to capture and quantify participants' affective experience throughout the interview.
Skiendziel et al., 


\begin{tabular}{|c|c|c|c|}
\hline Construct & Assessment & Brief description & Additional reading \\
\hline \multirow[t]{3}{*}{$\begin{array}{l}\text { Teller-listener } \\
\text { dynamics }\end{array}$} & $\begin{array}{l}\text { General } \\
\text { orientation to } \\
\text { interviewer and } \\
\text { rapport }\end{array}$ & $\begin{array}{l}\text { Dynamics between the participant and } \\
\text { interviewer may be captured via video } \\
\text { recording and quantified through a } \\
\text { consideration of a number of nonverbal } \\
\text { behaviors, including physical posture. }\end{array}$ & Hall et al., (1995) \\
\hline & Social behaviors & $\begin{array}{l}\text { The social behaviors demonstrated by the } \\
\text { participant, as captured via video recording, are } \\
\text { quantified along a number of dimensions, } \\
\text { including the degree of humor demonstrated by } \\
\text { the respondent. }\end{array}$ & Funder et al., (2000) \\
\hline & $\begin{array}{l}\text { Interpersonal } \\
\text { behaviors }\end{array}$ & $\begin{array}{l}\text { The dominant and nurturant behaviors } \\
\text { demonstrated by the participant and interview } \\
\text { may be assessed in real time using the } \\
\text { "computer joystick technique". }\end{array}$ & Sadler et al., (2015) \\
\hline Stress & $\begin{array}{l}\text { Physiological } \\
\text { processes }\end{array}$ & $\begin{array}{l}\text { Stress-based physiological responses may be } \\
\text { captured throughout the course of the } \\
\text { interview via the monitoring of heart rate and } \\
\text { electrodermal activity. }\end{array}$ & $\begin{array}{l}\text { Pressman et al., } \\
(2020)\end{array}$ \\
\hline Brain activity & $\begin{array}{l}\text { Neurological } \\
\text { processes }\end{array}$ & $\begin{array}{l}\text { Brain activity during recall of autobiographical } \\
\text { memories may be measured via a consideration } \\
\text { of the concentration of oxygen in blood at } \\
\text { different areas of the brain (as assessed via } \\
\text { fMRI). }\end{array}$ & $\begin{array}{l}\text { D'Argembeau et al., } \\
(2014)\end{array}$ \\
\hline
\end{tabular}

Note. Many of the additional readings specified in this table are not drawn specifically from the narrative identity literature and/or summarize work on narrative identity. These additional readings were selected on the basis of 1) the methodological techniques summarized therein, and 2) their conceptual content.

\section{On Process and Performance}

As this article made its way through the peer review processes, one of its reviewers expressed the opinion that we are not studying narrative identity per se when we focus our analysis on a few key scenes (e.g., high points, low points). From the reviewer's perspective, this is a less than ideal method to assess narrative identity's integrative nature (recognized here and elsewhere as a distinctive component of this construct; Syed et al., 2020). Although I am not sure I completely agree with this sentiment (many aspects of individual stories, such as self-event connections extend beyond the specific experience described, at least implying some sort of temporal integration; see Pasupathi et al., 2007), the reviewer's comment nevertheless leads to the valid question of potential ways in which integration may be better captured. This question can be considered in terms of both modifying 1) our assessment procedures, and 2) the ways in which data from the LSI is analyzed. I touch on each below. 


\section{Modifying Current Assessments}

When working to capture the integrative nature of narrative, there may be something to be said for embracing more process-based interview assessments. For example, Chandler and colleagues (2003) introduced a novel procedure to capture participants' reasoning about their own continuity through time. Doing so required that participants first generate a self-description from several years ago. They were next asked for a contemporary self-description. Invariably, the descriptions differed, often to the degree becoming of two numerically distinct individuals rather than a single soul at two points in time. It then fell to the participants to reason, or justify, their belief that they were the same person they once were. The elegance of this technique is that it puts participants on the spot, requiring that they work through the reasoning process of sameness in change while in the company of an interviewer and equipment documenting their unfolding narrative.

It seems likely that the degree to which the same theme or motif is expressed across stories holds at least partial relevance to the degree to which the storied self is unified and temporally integrated. Relations between-stories and within-persons have, however, only rarely been considered. To help accentuate this focus, it may prove profitable to prompt participants to themselves reflect on the ways in which the stories they have disclosed throughout the LSI do and do not align. One could imagine modifying some of the prompts pioneered in Chandler et al. (2003) to accomplish this aim. S-data could also be used to capture participants' views of the relations between their stories following their disclosure.

\section{Modifying Current Analytical Approaches}

Once stories have been collected and coded, narrative identity researchers have typically explored relations between features of individual stories and the outcome variable(s) of interest (e.g., Bauer et al., 2019) or, more commonly, aggregated ratings of these stories to the person level and then explore these aggregated values in relation to the outcome variable(s) of interest (e.g., McAdams et al., 2006). The few examinations of relations between stories within-persons have taken the form of (a) identifying the existence of the same theme across participants' stories (McLean \& Fournier, 2008), or (b) considering the degree of intra-individual variability across participants' stories (e.g., Dunlop, 2015; McLean et al., 2017; Pasupathi et al., 2020).

To stimulate further attempts to understand narrative identity, including the relations between prompts and its internal consistency, researchers could consider creating figures that represent the levels of a given narrative theme throughout the interview process (see Figure 2 for a hypothetical case). Adopting such visual representations would allow us to: 1) begin to explore narrative identity's normative profile, 2) compare normative profiles pertaining to the life stories of different domains (e.g., one's love life, one's 
professional life), and 3) visually represent the narrative identity profiles corresponding with outcomes of interest (e.g., the narrative profile of storytellers high relative to low in life satisfaction, high relative to low in generativity, etc.). The impetus for possibilities (1), (2), and (3) is furthered by the benefits seen within the personality trait literature from pursuing the equivalent (e.g., Biesanz \& Human, 2010), research showcasing variability in features of stories on the basis of the social role or life domain in which they are situated (e.g., Dunlop, 2015), and research noting varied relations between narrative features and certain outcome variables (e.g., well-being) across prompts (Bauer et al., 2019), respectively.

Figure 2

Hypothetical Case Example of Narrative Theme Throughout Life Story Interview (LSI)

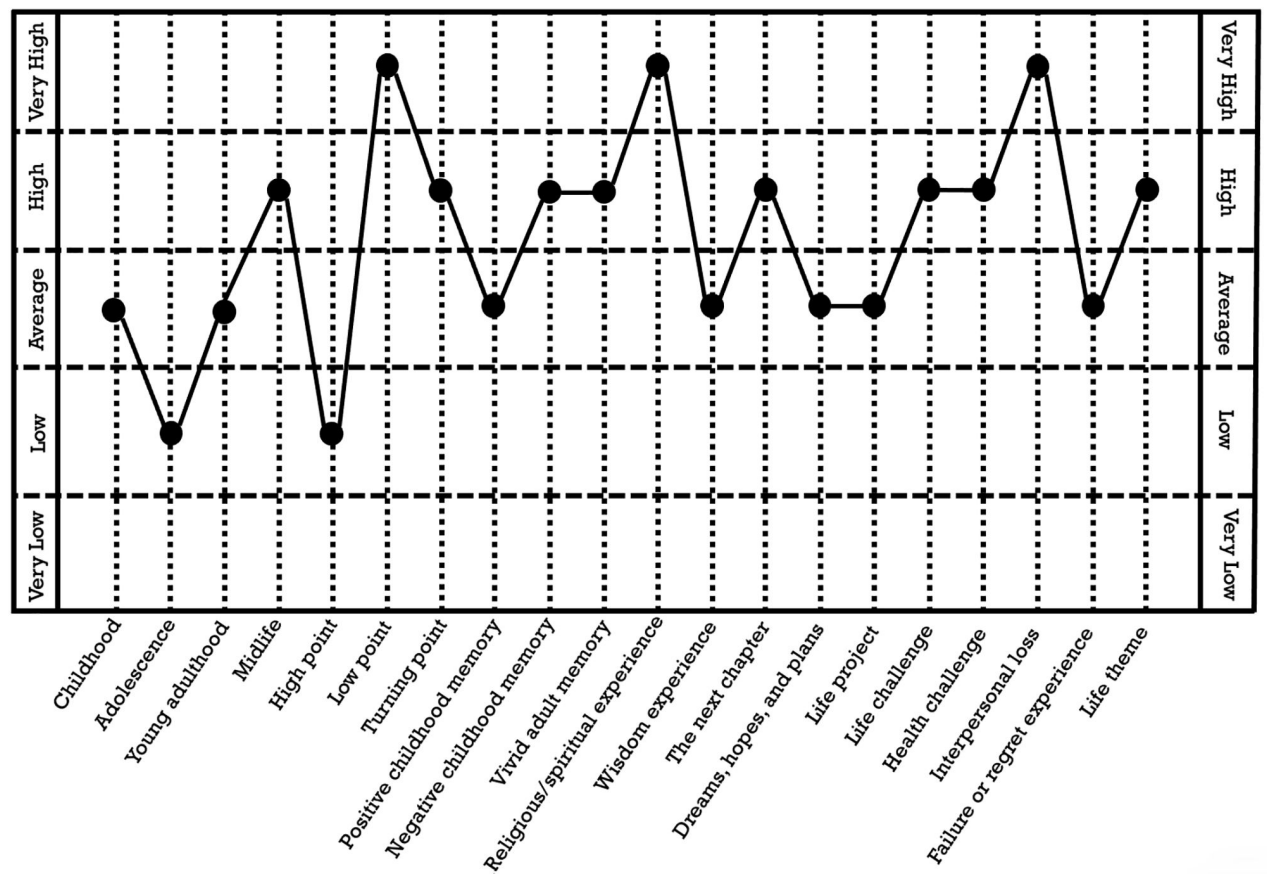

Note. Life chapters: "Childhood", "Adolescence", "Young adulthood", and "Midlife"; Key scenes in the life story: "High point", "Low point", "Turning point", "Positive childhood memory", "Negative childhood memory", "Vivid adult memory", "Religious/spiritual experience”, "Wisdom experience"; Future script: "The next chapter", "Dreams, hopes, and plans", "Life project"; Challenges; "Life challenge", "Health challenge", "Interpersonal loss", "Failure or regret experience"; Life theme: "Life theme". Personal ideology prompts are not presented in this hypothetical case. 


\section{Conclusion}

The promise of narrative identity research has never been greater. In the rearview there exists a validated method to both collect the narrative material that speaks to our central construct and quantify the thematic and structural features therein. I hope that my excitement for the future has been conveyed in the pages of this manuscript. This writing project was undertaken in the interest of recognizing several additional techniques and constructs pertinent to study of narrative identity. It provides narrative identity researchers with a number of options to supplement their assessment of participants' life chapters and key scenes. It also provides personality psychologists working outside of this literature with potential entry points from which to consider the stories by which our participants live.

Funding: The author has no funding to report.

Acknowledgments: I would like to thank the two reviewers at Personality Science as well as Dorthe Thomsen for their valuable comments on earlier versions of this manuscript. Finally, I would like to thank J. Rauthman for his encouragement to put pen to paper and write this article.

Competing Interests: The author has declared that no competing interests exist.

Author Contributions: William Dunlop-Idea, conceptualization | Design planning | Visualization (data presentation, figures, etc.) | Writing | Feedback, revisions | Project coordination, administration | Other.

Ethics Statement: No ethical issues and/or ethics approvals need to be disclosed.

Related Versions: No other previously published versions of this manuscript exist in part or in whole.

\section{References}

Adler, J. M. (2019). Stability and change in narrative identity: Introduction to the special issue on repeated narration. Qualitative Psychology, 6, 134-145. https://doi.org/10.1037/qup0000155

Adler, J. M., Dunlop, W. L., Fivush, R., Lilgendahl, J. P., Lodi-Smith, J., McAdams, D. P., McLean, K. C., Pasupathi, M., \& Syed, M. (2017). Research methods for studying narrative identity: A primer. Social and Personality Psychological Science, 8(5), 519-527.

https://doi.org/10.1177/1948550617698202

Adler, J. M., Lodi-Smith, J., Philippe, F. L., \& Houle, I. (2016). The incremental validity of narrative identity in predicting well-being: A review of the field and recommendations for the future. Personality and Social Psychology Review, 20(2), 142-175.

https://doi.org/10.1177/1088868315585068 
Bamberg, M. (2015). Who Am I? Narration and its contribution to self and identity. In B. Gough, (ed.), Qualitative research in psychology. Volume III: Methodologies 1 - From experiential to constructionist approaches (pp. 233-256). Sage Publications.

Bauer, J. J., Graham, L. E., Lauber, E. A., \& Lynch, B. P. (2019). What growth sounds like: Redemption, self-improvement, and eudaimonic growth across different life narratives in relation to well-being. Fournal of Personality, 87, 546-565. https://doi.org/10.1111/jopy.12414

Berntsen, D., \& Bohn, A. (2010). Remembering and forecasting: The relation between autobiographical memory and episodic future thinking. Memory \& Cognition, 38, 265-278. https://doi.org/10.3758/MC.38.3.265

Berntsen, D., \& Rubin, D. C. (2006). The centrality of events scale: A measure of integrating a trauma into one's identity and its relation to post-traumatic stress disorder symptoms. Behaviour Research and Therapy, 44(2), 219-231. https://doi.org/10.1016/j.brat.2005.01.009

Berntsen, D., Hoyle, R. H., \& Rubin, D. C. (2019). The Autobiographical Recollection Test (ART): A measure of individual difference in autobiographical memory. Journal of Applied Research in Memory and Cognition, 8(3), 305-318. https://doi.org/10.1016/j.jarmac.2019.06.005

Berntsen, D., Rubin, D. C., \& Salgado, S. (2015). The frequency of involuntary autobiographical memories and future thoughts in relation to daydreaming, emotional distress, and age. Consciousness and Cognition, 36, 352-372. https://doi.org/10.1016/j.concog.2015.07.007

Biesanz, J. C., \& Human, L. J. (2010). The cost of forming more accurate impressions: AccuracyMotivated perceivers see the personality of others more distinctively but less normatively than perceivers without an explicit goal. Psychological Science, 21(4), 589-594. https://doi.org/10.1177/0956797610364121

Blagov, P. S., \& Singer, J. A. (2004). Four dimensions of self-defining memories (specificity, meaning, content, and affect) and their relationships to self-restraint, distress, and repressive defensiveness. Journal of Personality, 72(3), 481-511.

https://doi.org/10.1111/j.0022-3506.2004.00270.x

Bluck, S., \& Alea, N. (2011). Crafting the TALE: Construction of a measure to assess the functions of autobiographical remembering. Memory, 19(5), 470-486. https://doi.org/10.1080/09658211.2011.590500

Boyd, R. L., Pasca, P., \& Lanning, K. (2020). The personality panorama: Conceptualizing personality through big behavioral data. European fournal of Personality, 34(5), 599-612. https://doi.org/10.1002/per.2254

Bruner, J. S. (1986). Actual minds, possible worlds. Harvard University Press.

Cabeza, R., \& St. Jacques, P. (2007). Functional neuroimaging of autobiographical memory. Trends in Cognitive Sciences, 11(5), 219-227. https://doi.org/10.1016/j.tics.2007.02.005

Chandler, M. J., Lalonde, C. E., Sokol, B. W., \& Hallett, D. (2003). Personal persistence, identity development, and suicide: A study of Native and Non-native North American adolescents. Monographs of the Society for Research in Child Development, 68(2), vii-130. 
Connelly, B. S., \& Ones, D. S. (2010). An other perspective on personality: Meta- analytic integration of observers' accuracy and predictive validity. Psychological Bulletin, 136(6), 1092-1122. https://doi.org/10.1037/a0021212

D’Argembeau, A., Cassol, H., Phillips, C., Balteau, E., Salmon, E., \& Van der Linden, M. (2014). Brains creating stories of selves: The neural basis of autobiographical reasoning. Social Cognitive and Affective Neuroscience, 9(5), 646-652. https://doi.org/10.1093/scan/nst028

Dunlop, W. L. (2015). Contextualized personality, beyond traits. European fournal of Personality, 29(3), 310-325. https://doi.org/10.1002/per.1995

Dunlop, W. L. (2019). Love as story, love as storytelling. Personal Relationships, 26(1), 114-136. https://doi.org/10.1111/pere.12271

Dunlop, W. L. (2021). Everything you wanted to know about redemptive stories* (*but were afraid to ask). Journal of Research in Personality, 92, Article 104078. https://doi.org/10.1016/j.jrp.2021.104078

Dunlop, W. L., Harake, N., Wilkinson, D., \& Graham, L. (2020). On rhetoric and ratings: Assessing narrative identity via conceptual coding and self-ratings. fournal of Research in Personality, 85, Article 103922. https://doi.org/10.1016/j.jrp.2020.103922

Dunlop, W. L., Lee, D., McCoy, T. P., Harake, N., Wilkinson, D., Graham, L. E., \& Miller, T. J. (2020). The stories we tell, the reputations we form: Narrative identity and person perception. fournal of Research in Personality, 89, Article 104023. https://doi.org/10.1016/j.jrp.2020.104023

Dunlop, W. L., McCoy, T. P., Harake, N., \& Gray, J. (2018). When I think about you I project myself: Examining idiographic goals from the perspective of self and other. Social and Personality Psychological Science, 9(5), 586-594. https://doi.org/10.1177/1948550617715069

Dunlop, W. L., Wilkinson, D., Harake, N., Graham, L. E., \& Lee, D. (2020). The redemption and contamination research form: Exploring relations with narrative identity, personality traits, and life satisfaction. Memory, 28(10), 1219-1230. https://doi.org/10.1080/09658211.2020.1828926

Hall, J. A., Harringan, J. A., \& Rosenthal, R. (1995). Nonverbal behavior in clinical-patient interaction. Applied \& Preventive Psychology, 4(1), 21-37.

https://doi.org/10.1016/S0962-1849(05)80049-6

Harake, N. R., McCoy, T. P., Lee, D., \& Dunlop, W. L. (2020). Narrating the other: Self-other agreement of affective qualities and manifest events among personal life stories and the vicarious life stories provided by informants. Fournal of Research in Personality, 89, Article 104037. https://doi.org/10.1016/j.jrp.2020.104037

Harake, N. R., Wilkinson, D. E., Sweeny, K., \& Dunlop, W. L. (2020). Narrating the nadir: Examining personal and vicarious stories of cancer-related low points among survivors and romantic partners. Psychology \& Health, 35(10), 1268-1292. https://doi.org/10.1080/08870446.2020.1743838

Harringan, J. A., Rosenthal, R., \& Scherer, K. R. (2005). The new handbook of methods in nonverbal behavior research. Oxford University Press.

Haskard, K. B., Williams, S. L., DiMatteo, M. R., Heritage, J., \& Rosenthal, R. (2008). The provider's voice: Content-filtered speech of nurses and physicians in primary medical care. fournal of Nonverbal Behavior, 32, 1-20. https://doi.org/10.1007/s10919-007-0038-2 
Hopwood, C. J., Pincus, A. L., \& Wright, A. G. C. (2021). Six assumptions of contemporary integrative interpersonal theory of personality and psychopathology. Current Opinion in Psychology, 41, 65-70. https://doi.org/10.1016/j.copsyc.2021.03.007

Funder, D. C. (2019). The personality puzzle (8th ed.). Norton.

Funder, D. C., Furr, R. M., \& Colvin, C. R. (2000). The Riverside Behavioral Q-sort: A tool for the description of social behavior. fournal of Personality, 68(3), 451-489.

https://doi.org/10.1111/1467-6494.00103

Hallford, D. J., \& Mellor, D. (2017). Development and validation of the Awareness of Narrative Identity Questionnaire (ANIQ). Assessment, 24(3), 399-413.

https://doi.org/10.1177/1073191115607046

Jensen, R. A. A., Thomsen, D. K., O’Connor, M., \& Mehlsen, M. Y. (2020). Age differences in life stories and neuroticism mediate age difference in subjective well-being. Applied Cognitive Psychology, 34(1), 3-15. https://doi.org/10.1002/acp.3580

Luchetti, M., \& Sutin, A. R. (2016). Measuring the phenomenology of autobiographical memory: A short form of the Memory Experiences Questionnaire. Memory, 24(5), 592-602. https://doi.org/10.1080/09658211.2015.1031679

McAdams, D. P. (1985). Power intimacy and the life story: Personological inquiries into identity. Guilford Press.

McAdams, D. P. (1987). A life-story model of identity. In R. Hogan \& W. H. Jones (Eds.), Perspectives in personality (Vol. 2, pp. 15-50). JAI Press.

McAdams, D. P. (1990). Unity and purpose in human lives: The emergence of identity as the life story. In A. I. Rabin, R. A. Zucker, R. A. Emmons, \& S. Frank (Eds.), Studying persons and lives (pp. 148-200). Springer.

McAdams, D. P. (2013). The redemptive self: Stories Americans live by (2nd ed.). Oxford University Press.

McAdams, D. P. (2008). The life story interview. Unpublished manuscript. Northwestern University.

McAdams, D. P., Bauer, J., Sakaeda, A., Anyidoho, N., Machado, M., Magrino-Failla, K., White, K. W., \& Pals, J. L. (2006). Continuity and change in the life story: A longitudinal study of autobiographical memories in emerging adulthood. Journal of Personality, 74(5), 1371-1400. https://doi.org/10.1111/j.1467-6494.2006.00412.x

McAdams, D. P., \& Pals, J. L. (2006). A new big five: Fundamental principles for an integrative science of personality. The American Psychologist, 61(3), 204-217. https://doi.org/10.1037/0003-066X.61.3.204

McAdams, D. P., Diamond, A., de St. Aubin, E., \& Mansfield, E. (1997). Stories of commitment: The psychosocial construction of generative lives. Journal of Personality and Social Psychology, 72(3), 678-694. https://doi.org/10.1037/0022-3514.72.3.678

McCoy, T. P., \& Dunlop, W. L. (2016). Contextualizing narrative identity: A consideration of assessment settings. Fournal of Research in Personality, 65, 16-21.

https://doi.org/10.1016/j.jrp.2016.08.006 
McLean, K. C. (2015). The Co-authored Self: Family Stories and the Construction of Personal Identity. Oxford University Press.

McLean, K. C., Delker, B. C., Dunlop, W. L., Salton, R., \& Syed, M. (2020a). Redemptive stories and those who tell them are preferred in the U.S. Collabra. Psychology, 6(1), Article 40. https://doi.org/10.1525/collabra.369

McLean, K. C., \& Fournier, M. A. (2008). The content and processes of autobiographical reasoning in narrative identity. Journal of Research in Personality, 42(3), 527-545.

https://doi.org/10.1016/j.jrp.2007.08.003

McLean, K. C., \& Lilgendahl, J. P. (2008). Why recall our highs and lows: Relations between memory functions, age, and well-being. Memory, 16(7), 751-762.

https://doi.org/10.1080/09658210802215385

McLean, K. C., Pasupathi, M., Greenhoot, A., \& Fivush, R. (2017). Does intra-individual variability in narration matter and for what? Journal of Research in Personality, 69, 55-66. https://doi.org/10.1016/j.jrp.2016.04.003

McLean, K. C., Syed, M., Pasupathi, M., Adler, J. M., Dunlop, W. L., Drustrup, D., Fivush, R., Graci, M. E., Lilgendahl, J. P., Lodi-Smith, J., McAdams, D. P., \& McCoy, T. P. (2020). The empirical structure of narrative identity: The initial big three. Fournal of Personality and Social Psychology, 119(4), 920-944. https://doi.org/10.1037/pspp0000247

Palombo, D. J., Williams, L. J., Abdi, H., \& Levine, B. (2013). The survey of autobiographical memory (SAM): A novel measure of trait mnemonics in everyday life. Cortex, 49(6), 1526-1540. https://doi.org/10.1016/j.cortex.2012.08.023

Panattoni, K., \& Thomsen, D. K. (2018). My partner's stories: Relations between personal and vicarious life stories within romantic couples. Memory, 26(10), 1416-1429. https://doi.org/10.1080/09658211.2018.1485947

Pasupathi, M. (2015). Autobiographical reasoning and my discontent: Alternative paths from narrative to identity. In K. C. McLean \& M. Syed (Eds.), Oxford library of psychology: The Oxford handbook of identity development (pp. 166-181). Oxford University Press.

Pasupathi, M., Fivush, R., Greenhoot, A. F., \& McLean, K. C. (2020). Intraindividual variability in narrative identity: Complexities, garden paths, and untapped research potential. European Journal of Personality, 34(6), 1138-1150. https://doi.org/10.1002/per.2279

Pasupathi, M., Mansour, E., \& Brubaker, J. R. (2007). Developing a life story: Constructing relations between self and experience in autobiographical narratives. Human Development, 50, 85-110. https://doi.org/10.1159/000100939

Paulhus, D. L., \& Vazire, S. (2007). The self-report method. In R. W. Robins, R. C. Fraley, \& R. F. Krueger (Eds.), Handbook of research methods in personality psychology (pp. 224-239). Guilford Press.

Pressman, S. D., Acevedo, A. M., Hammond, K. V., \& Kraft-Feil, T. L. (2020). Smile (or grimace) through the pain? The effects of experimentally manipulated facial expressions on needleinjection responses. Emotion. Advance online publication. https://doi.org/10.1037/emo0000913 
Rubin, D. C. (2020). Self-concept focus: A tendency to perceive autobiographical events as central to identity. Fournal of Applied Research in Memory and Cognition, 9(4), 576-586. https://doi.org/10.1016/j.jarmac.2020.06.001

Rubin, D. C., Dennis, M. F., \& Beckham, J. C. (2011). Autobiographical memory for stressful events: The role of autobiographical memory in posttraumatic stress disorder. Consciousness and Cognition, 20(3), 840-856. https://doi.org/10.1016/j.concog.2011.03.015

Sadler, P., Woody, E., McDonald, K., Lizdek, I., \& Little, J. (2015). A lot can happen in a few minutes: Examining dynamic patterns within an interaction to illuminate the interpersonal nature of personality disorders. Journal of Personality Disorders, 29(4), 526-546.

https://doi.org/10.1521/pedi.2015.29.4.526

Skiendziel, T., Rösch, A. G., \& Schultheiss, O. C. (2019). Assessing the convergent validity between the automated emotion recognition software Noldus Facereader 7 and Facial Action Coding System scoring. PLOS ONE, 14, Article e0223905. https://doi.org/10.1371/journal.pone.0223905

Syed, M., DeYoung, C. G., \& Tiberius, V. (2020). Self, motivation, and virtue, or: How we learned to stop worrying and love deep integration. In N. E. Snow \& D. Narvaez (Eds.), Self, motivation, and virtue: Innovative interdisciplinary research (pp. 7-24). Routledge.

Thomsen, D. K., Panattoni, K., Allé, M. C., Wellnitz, K. B., \& Pillemer, D. B. (2020). Vicarious life stories: Examining relations to personal life stories and well-being. Journal of Research in Personality, 88, Article 103991. https://doi.org/10.1016/j.jrp.2020.103991

Thomsen, D. K., \& Pillemer, D. B. (2017). I know my story and I know your story: Developing a conceptual framework for vicarious life stories. Journal of Personality, 85(4), 464-480. https://doi.org/10.1111/jopy.12253

Thorne, A., Cutting, L., \& Shaw, D. (1998). Young adults' relationship memories and the life story: Examples or essential landmarks. Narrative Inquiry, 8(2), 237-268. https://doi.org/10.1075/ni.8.2.02tho

Vazire, S. (2010). Who knows what about a person? The self-other knowledge asymmetry (SOKA) model. Journal of Personality and Social Psychology, 98(2), 281-300. https://doi.org/10.1037/a0017908

Webster, J. D. (1997). The Reminiscence Functions Scale: A replication. International fournal of Aging \& Human Development, 44(2), 137-148. https://doi.org/10.2190/AD4D-813D-F5XN-W07G Wiggins, J. S. (2003). Paradigms of Personality Assessment. Guilford Press.

Willems, R. M., Nastase, S. A., \& Milivojevic, B. (2020). Narratives for neuroscience. Trends in Neurosciences, 43(5), 271-273. https://doi.org/10.1016/j.tins.2020.03.003 


\section{eapp}

Personality Science (PS) is an official journal of the European Association of Personality Psychology (EAPP).
(P) leibniz-psychology.org

PsychOpen GOLD is a publishing service by Leibniz Institute for Psychology (ZPID), Germany. 